\title{
Original
}

\section{The Effect of Bisphosphonate on Bone Formation After Tooth Extraction in Ovariectomized Rats}

\author{
Takaki Yamazaki, Nobuhiko Hiruma, YasuoMiake, MitukoMoriguti, Takashi Sawada, \\ Hitoshi Yamamoto and Takaaki Yanagisawa
}

Department of Ultrastructural Science, Tokyo Dental College, Tokyo, Japan

(Accepted for publication, September 26, 2013)

\begin{abstract}
Because dentists often see patients who are taking bisphosphonate (BIS) drugs, it is important for dentists to be aware of bisphosphonate-related osteonecrosis of the jaw (BRONJ). However, many aspects of the pathogenesis of BRONJ have not yet been clarified. The present study examined the healing process of tooth extraction sockets in ovariectomized rats to elucidate the pathogenesis of BRONJ, particularly the impact of BIS administration in new bone formation. Nine-week old female Wistar rats (6 weeks old during surgical removal of the ovaries) were divided into control (saline treated) and BIS-treated groups (6 in each condition). Alendronate was used for BIS treatment. The maxillary second molar was extracted. Specimens were decalcified with EDTA and embedded in paraffin for serial section. New bone formation and osteoclast counts were determined in $\mathrm{H}-\mathrm{E}$ and tartrate-resistant acid phosphatase stain, respectively. Bone mineral density was also measured using micro-CT in non-decalcified samples. Contact microradiography (CMR) was taken in polished specimens. Granulation tissue was observed in extraction sockets of both groups at 1 week, and new bone formation was observed at 4 weeks. In the BIS-treated group, the number of multinucleated osteoclasts away from the bone surface increased. New bone formation after tooth extraction increased over time, but it was clearly less in the BIS-treated group compared to the control group. Results showed that BIS inhibited the formation of new bone at extraction socket during the early stage, causing low-density bone trabeculae and the spread of abnormal osteoclasts leading to BRONJ.
\end{abstract}

Key words: Bisphosphonate, Alendronate, Tooth extraction, Osteoclasts

\section{Introduction}

Bisphosphonate (BIS) is a drug used to treat osteoporosis and Paget's disease and has an effect on bone resorption ${ }^{1-3)}$. Moreover, it is also used in the treatment of malignancy associated with hypercalcemia including the prevention of bone metastasis in malignant tumors ${ }^{4,5}$.

Due to the increase in the number of patients with osteoporosis recently, the chance of encountering patients taking BIS for dentists also increased. Thus, dentists must be aware of the socalled Bisphosphonate-Related Osteonecrosis of the Jaw (BRONJ) in treating patients under BIS treatment ${ }^{6,7)}$. Numerous studies in Europe and America have reported the occurrence of BRONJ, however, the pathogenesis is still unknown ${ }^{8,9)}$.

Failure of extraction socket to heal was shown to be an early symptom of BRONJ and invasive dental procedures such as tooth extraction is an important factor in BRONJ ${ }^{10,11)}$. Therefore, to find

Correspondence to: Dr. Takaki Yamazaki, Department of Ultrastructural Science, Tokyo Dental College, 2-9-18 Misakicho Chiyoda-ku, Tokyo, 101-0061 Japan; Tel: 03-6380-9274; Email: yamazakitakaki@tdc.ac.jp the effect of BIS on the healing of tooth extraction socket would be a stepping-stone to reveal the mechanism of BRONJ.

Patients with osteoporosis are more than $80 \%$ women in which the decrease in female hormones after menopause may be the major cause. The rapid decrease in estrogen after menopause has a major effect in bone throughout the body but it is not clear whether it has the same effect in alveolar bone.

After administration, BIS is deposited in bone and its pharmacological effect is on osteoclasts, which destroy bone by phagocytosis. The basic mechanism of action is the inhibition of farnesyl pyrophosphate synthase, which can cause apoptosis of osteoclasts ${ }^{12,13)}$. Alendronate is a typical second generation BIS used in this experiment. Studies showed that Alendronate is the most extensive clinical drug for the prevention of fractures ${ }^{14,15)}$ and has strong inhibition of bone resorption by inducing apoptosis of osteoclasts, thus becoming the first line in the treatment of osteoporosis $^{14,16)}$. Moreover, it is also used in the treatment of malignant tumor with hypercalcemia in Japan ${ }^{17}$.

A study of postmenopausal osteoporosis in ovariectomized 
rat is the most commonly used animal model and many basic data have been gathered so far ${ }^{18,19)}$. Thus, the animal model can be used to examine the healing of tooth extraction socket healing in postmenopausal osteoporosis administered with BIS. The aim of the study was to determine the effect of BIS administration in the healing process after tooth extraction in ovariectomized rats with reduced estrogen and to clarify the pathogenesis of BRONJ in postmenopausal osteoporosis

\section{Materials and Methods}

Alendronate Sodium Hydrate (Tiroc $®$ Injection $10 \mathrm{mg}$, Teijin Pharma, Tokyo) was used for BIS treatment. The drug was administered through intraperitoneal injection with a dose of 20 microgram per $100 \mathrm{~g}$ body weight $(0.2 \mathrm{mg} / \mathrm{g})$.

Thirty, 9-week old (about $180 \mathrm{~g}$ ) Wistar ovariectomized rats (OVX rats, Sankyo Lab Service, Tokyo; ovariectomy was done at 6 weeks old) were used in the study. The OVX rats were divided into 2 groups, control and BIS-treated groups. The drugs were first administered at 9 weeks old. For the control group, saline water was administered in the same manner and amount. The maxillary second molar on both sides of the jaw (M2) were extracted at age 10 weeks in both groups. Dental hand instruments (YDM, Tokyo) were used for tooth extraction. Pentobarbital (30$40 \mathrm{mg} / \mathrm{kg}$ ) and diethyl ether were used for general anesthesia. Postoperative medications were administered to each group once after tooth extraction. Then after, the animals were sacrificed at 1 , 2 and 4 weeks by pentobarbital overdose. The maxillary bone with the remaining molars were collected as samples and fixed in $10 \%$ formaldehyde. The groups were further divided into nondecalcified and decalcified groups. The experiment was approved by Tokyo Dental College Animal Experiment Committee (approval number 250202).

Samples were decalcified in 10\% EDTA ( $\mathrm{pH} 7.3)$ at room temperature for 28 days. Then after, the samples were placed in series of alcohol following routine fixation, embedded in paraffin block and sectioned into $5 \mathrm{~mm}$ thickness. Samples were stained with H-E and tartrate-resistant acid phosphate (TRAP, TRAP/ALP stain kit, Wako Pure Chemical Industries, Tokyo) to mark the osteoclasts. Specimens were examined under the light microscope. The presence of new bone in the extraction socket, number of TRAP-positive cells and size of new bone were measured. With respect to the number of TRAP-positive cells, the cells deposited on the bone surface and those that were detached from the bone surface were counted separately. Measurement was done on the palatal side of the mesial root of the extraction socket and the range was determined from the center of the crest of the alveolar bone of maxillary first molar (M1) to the line connecting the cavity wall surrounding the extraction socket. The range was determined in terms of the number of unit area $(1 \mathrm{~mm} \times 1 \mathrm{~mm})$ per number of measurements.

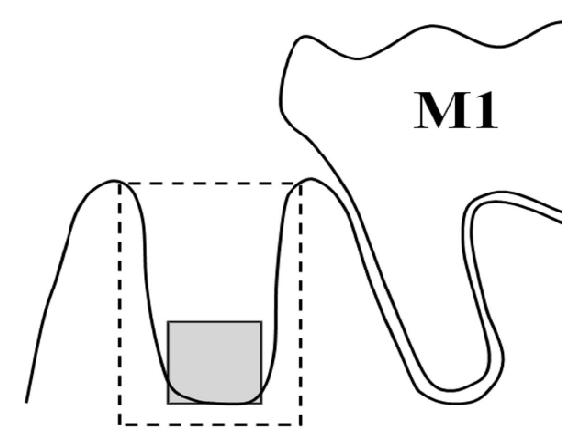

Figure 1. Schematic diagram of the area of measurement Dashed line: number of osteoclasts Solid line: bone density of volume

The non-decalcified group was dehydrated in increasing series of alcohol in a routine manner and embedded in polyester resin (Nissin EM, Tokyo Rigolac). Tomography was taken using microCT (HMX225=ACTIS +4 TESCO, Tokyo) with the following conditions; thickness of 50 micrometer, voltage of $140 \mathrm{kV}$, current of $140 \mathrm{iA}$ and SID/SOD of 600/60. Focusing range was from the mesial surface of M1 to the distal surface of the maxillary third molar (M3). CT images were taken using TRI3D-BON (Ratoc, Engineering, Tokyo) configuring the 3D image to measure the bone density of the mesial root plate of M2 extraction socket. Measurement range was set to $1 \mathrm{~mm}^{3}$ on the floor and one side the wall of socket (Fig. 1).

For a detailed observation of calcification, a polished specimen of 100-micrometer thickness from the sample block was prepared using Soft X-ray generator (CMR-3, SOFTEX, Tokyo) for contact microradiography (CMR). Radiograph was taken with a voltage of $15 \mathrm{kV}$, a current of $3 \mathrm{~mA}$, a focus distance of $44.4 \mathrm{~mm}$ and an exposure time of $13 \mathrm{~min}$. Glass plates (HRP-SN-2 2X2 30Z, KONIKA MINORTA OPTO, TOKYO) were used for the imaging. Developing was done for $5 \mathrm{~min}$ at $20{ }^{\circ} \mathrm{C}$ using a developing solution (D-19, Kodak, USA), fixed, washed and dried. Plates were then covered with glass.

The number TRAP-positive cells at the extraction socket was counted and subjected to multiple comparative test using nonrepeated measures of ANOVA and SNK test to compare between groups. A p-value of $<0.05$ was considered significant.

\section{Results}

\section{H-E stain}

One week after tooth extraction, the socket is filled with granulation tissue in both control and BIS-treated groups. In the control group, fine immature bone extending from the extraction socket wall was observed. Newly formed bone extended from the socket wall toward the middle of the extraction socket. Osteoblasts were observed near the edge of the apical third of the extraction socket. Granulation tissue was seen at the center of the extraction socket as well as an image of reminiscent osteoid (Fig. 2a, b). 
Takaki Yamazaki et al: Effect of Bisphosphonate after Tooth Extraction in Ovariectomized Rats
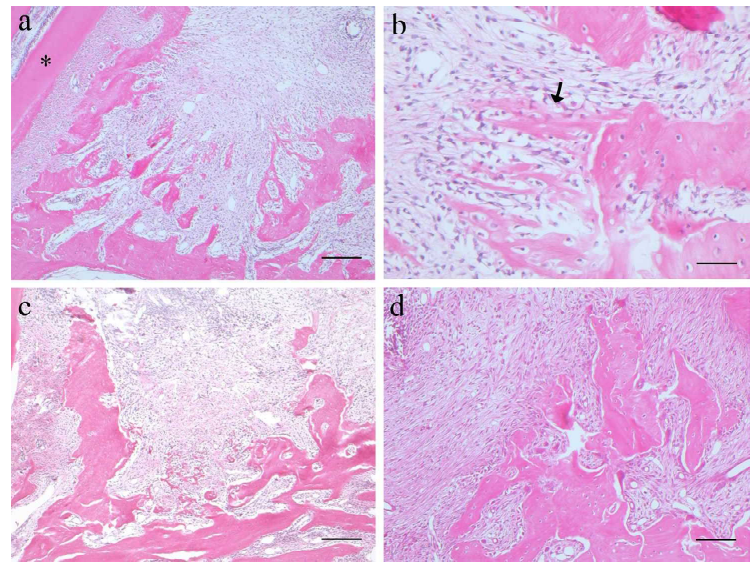

Figure 2. One week after tooth extraction, H-E stain.

a: Control group, low magnification.

Extraction socket is filled with granulation tissue; formation of new bone $(*)$ progressed toward the middle of the extraction socket near the edge of the apical third. Bars $=200 \mu \mathrm{m} *$ : Root of M1 b: Control group, high magnification.

Fine, immature new bone (Allow) extending from the socket wall can be observed, osteoblast-like cells can be seen at the periphery. Bars $=50 \mu \mathrm{m}$

c: BIS-treated group, low magnification.

Formation of few, immature new bone was observed on the floor of the extraction socket. Prominent resorption of the interalveolar septum near the apex was not observed. Bars $=200 \mu \mathrm{m}$ d: BIS-treated group, high magnification.

Newly formed bone can hardly be seen the extraction socket. Bars $=50 \mu \mathrm{m}$

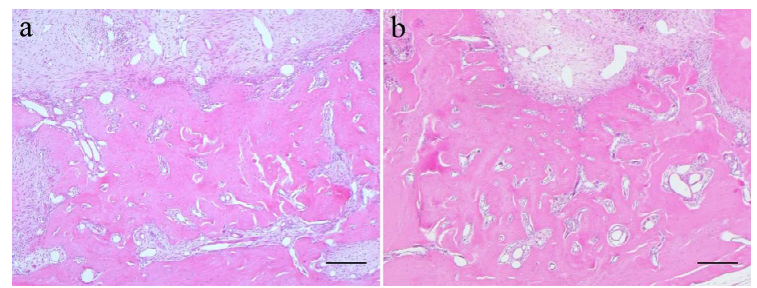

Figure 4. Four weeks after tooth extraction, H-E stain.

a: Control group: The newly formed bone in the interalveolar septum became enlarged and matured; the trabecular bone became bone-like structure, which is dense and thick; the boundary surrounding the integral part of the bone disappeared

b: BIS-treated group: The bone became dense but still few in amount; granulation tissue can still be seen; the boundary between the alveolar bone and new bone is relatively clear.

Bars $=200 \mu \mathrm{m}$

Resorption of the interalveolar septum around the edges of the extraction socket was also noted. In BIS-treated group, only a small amount of new, immature bone was observed on the wall and floor of extraction socket (Fig. 2c, d). Resorption of the interalveolar septum reaching the apical end was detected (Fig. 2d).

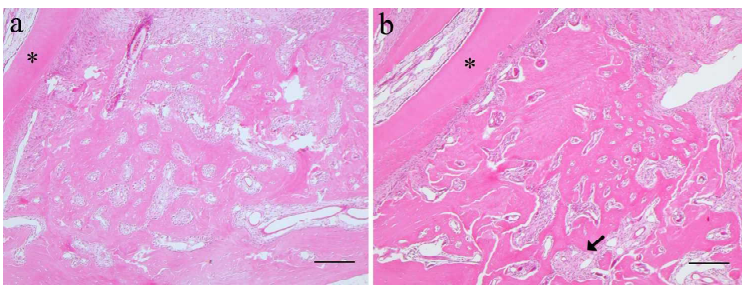

Figure 3. Two weeks after tooth extraction, H-E stain. a: Control group: Almost the entire extraction socket is filled with new bone, which is cancellous in structure and granulation tissue can still be seen inside. Interalveolar septum is mostly resorbed; the surrounding alveolar bone border is unclear.

b: BIS-treated group: Newly formed bone on the floor and walls of extraction site has an irregular mesh, there is a wide gap filled with granulation tissue (Arrow). The newly formed bone formed as part of the wall of extraction socket is less porous.

$*$ Root of M1 Bars $=200 \mu \mathrm{m}$

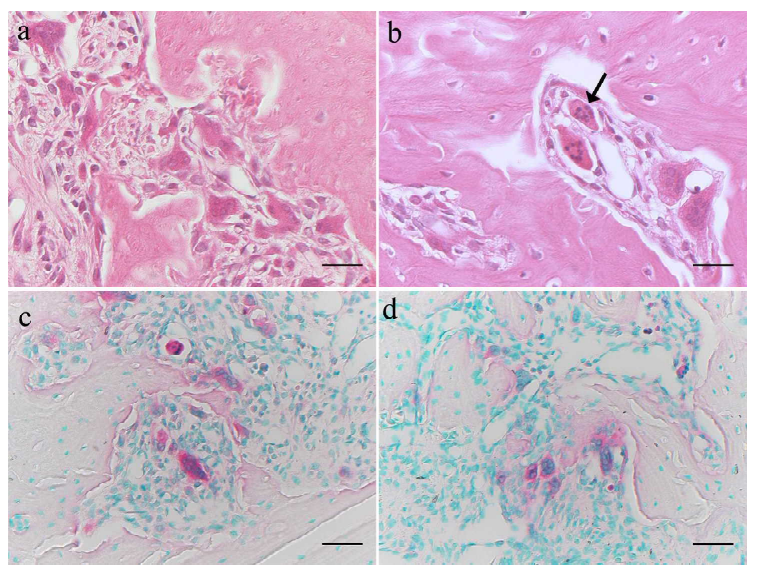

Figure 5.a: Four weeks after tooth extraction, BIS-treated group, H-E stain. Many small osteoclasts are seen away from the bone surface.

b: Four weeks after tooth extraction, BIS-treated group, H-E stain. There is abnormal aggregation of nuclei in osteoclasts. They are also located away from the bone surface (Arrow).

c: Two weeks after tooth extraction, BIS-treated group, TRAP stain.

Many TRAP-positive cells away from the bone surface can be seen. The ruffled border was also obscured.

d: Four weeks after tooth extraction, BIS-treated group, TRAP stain.

Multinucleated TRAP-positive cells are seen away from the bone surface. $\quad$ Bars $=50 \mu \mathrm{m}$

Two weeks after extraction, almost the entire socket was filled with new bone in both groups. In the control group, new bone or cancellous bone-like structure was formed in the socket surrounded by osteoblasts and granulation tissue. Most of the interalveolar septum was resorbed and replaced with new bone but the border surrounding the alveolar bone and the floor of the socket wall remained unclear (Fig. 3a). In BIS-treated group, the newly formed 


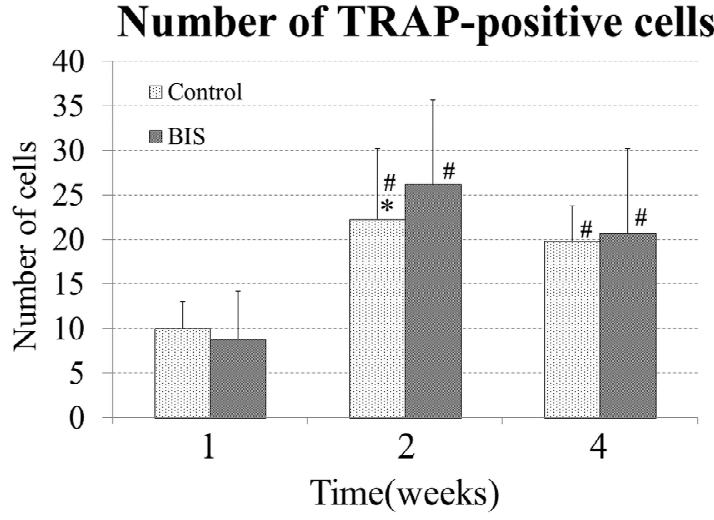

Figure 6. Number of TRAP-positive cells.

The number of TRAP positive cells in both control and BIS-treated groups is significantly higher in 2 weeks compared to 1 week $(\mathrm{P}<0.05)$. The number of TRAP-positive cells tends to decrease from 2 to 4 weeks although no significant difference was observed. Neither a significant difference was observed in each week between the control and BIS-treated group. * vs. Control 1w \# vs. BIS 1w

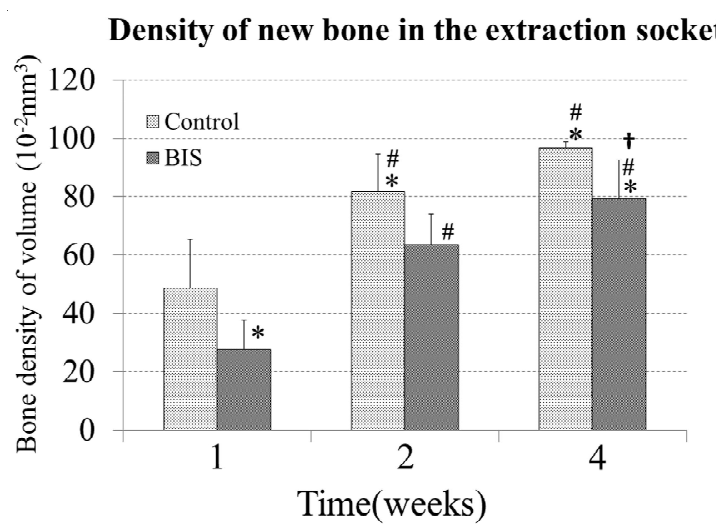

Figure 8. Density of volume new bone in the extraction socket. In both groups, bone density at 2 weeks is significantly higher than 1 week $(\mathrm{P}<0.05)$. Comparing both groups from 1 to 4 weeks, BIS-treated group has less density $(\mathrm{P}<0.01)$.

* vs. Control 1w \# vs. BIS 1w † vs. Control 4w

bone in the socket has an irregular mesh with a wide gap in between the floor of the socket and granulation tissue (Fig. 3b). Moreover, the newly formed bone lacks the bone-like fiber bundle with thickening of the cavity wall. Furthermore, a relatively clear boundary was observed between the newly formed bone and the socket wall (Fig. 3b).

Four weeks after extraction, the new bone in the socket has matured; bone quality was better and became denser in both groups. In the control group, the trabecular bone became thick compact bone; the boundary surrounding the alveolar bone disappeared and became an integral part of the bone structure (Fig. 4a). In BIS-treated group, the bone became denser in quality although still filled with gaps of granulation tissue and the

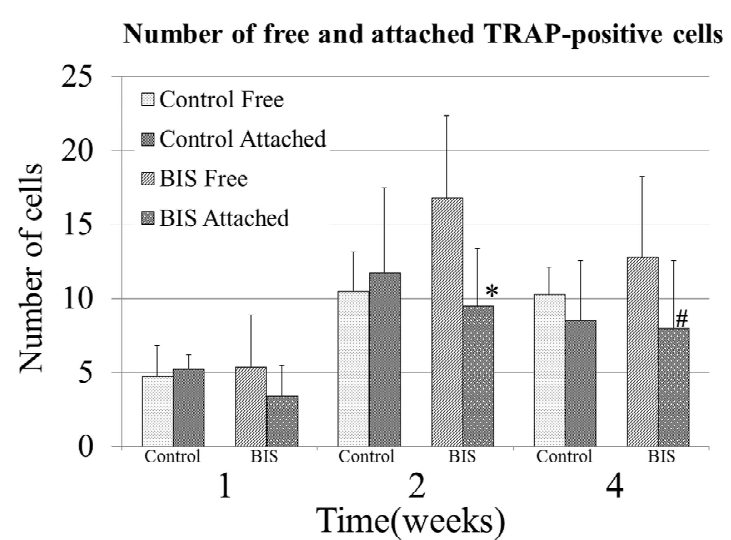

Figure 7. Number of free and attached TRAP-positive cells.

The control group showed no significant difference at 1 week. In BIS-treated group, free cells were more than the attached cells in each week. Significant difference in the number of cells was observed at 2 and 4 weeks $(\mathrm{P}<0.05)$ * vs. BIS Free $2 \mathrm{w} \quad \#$ vs. BIs Free $4 \mathrm{w}$

boundary between alveolar bone and new bone was relatively clear (Fig. 4b). Lack of ruffled border and several multinucleated bone cells with various abnormalities situated away from the bone surface were observed away (Fig. 5a, b).

\section{TRAP staining}

One week after extraction, in the control group, although TRAP-positive cells in the socket wall were not expected, multinucleated bone cells were seen in the bone marrow of the alveolar bone and in the resorbed interalveolar septum. TRAPpositive cells were also observed in BIS-treated group in a similar trend with the control group except near the intervalveolar septum. Two weeks after extraction, in the control group, TRAP-positive cells corresponding to bone resorption were noted. In BIS-treated group, TRAP-positive cells with abnormal nuclear condensation were found away from the bone surface. The ruffled border was also obscured (Fig. 5c). Even four weeks after extraction, in BIStreated group, the ruffled border was still unclear and the multinucleated cells were still noted away from the bone surface. Furthermore, the multinucleated osteoclasts are smaller than the usual, TRAP-positive cells were also present in the surrounding connective tissue away from the bone surface (Fig. 5d).

Comparing the number of TRAP-positive cells per unit area, the number increased significantly at 2 weeks compared to 1 week in both control and BIS-treated groups $(\mathrm{P}<0.05)$. However, no significant difference was observed between 4 and 2 weeks (Fig. 6). Neither a significant difference was observed between control and BIS-treated groups in each week.

Comparing the percentage of TRAP-positive cells, which were either free or attached to the bone surface, no significant difference was obtained in each week for the control group. However, in BIS-treated group, free cells were more compared to attached 
Takaki Yamazaki et al: Effect of Bisphosphonate after Tooth Extraction in Ovariectomized Rats

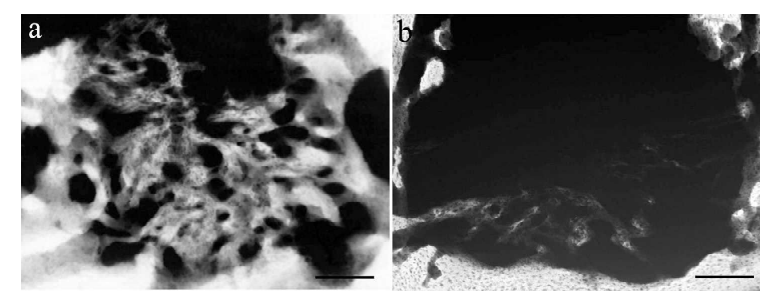

Figure 9. One week after tooth extraction, CMR image. a: Control group: The immature woven bone in the extraction socket is irregular with a weak degree of mineralization.

b: BIS-treated group: The extraction site is almost devoid of new bone with a small amount of woven bone near the floor of the socket. $\quad$ Bars $=100 \mu \mathrm{m}$

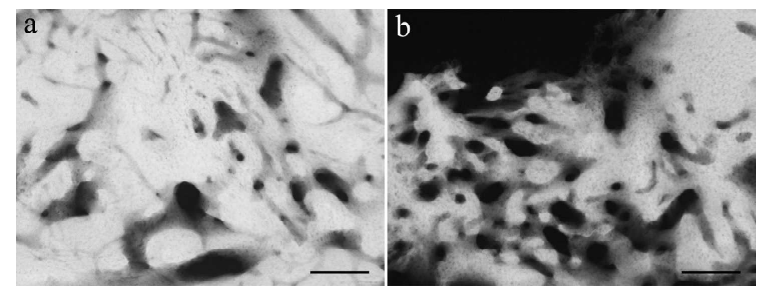

Figure 11. Four weeks after tooth extraction, CMR image. a: Control group: Extraction socket became unclear, the degree of calcification increased, bone trabeculae became thick; an overall high density of bone was observed.

b: BIS-treated group: Compared to 2 weeks, calcification and degree of bone density increased. However, bone density is lower compared to the control group, the trabecular bone is highly irregular. Bars $=100 \mu \mathrm{m}$

cells in each week. Significant difference was observed in 2 and 4 weeks $(\mathrm{P}<0.05$, Fig. 7$)$.

\section{Micro-CT image}

Measuring the bone density of the mesial palatal root of M2 in each week, an increase in bone density of volume was observed in the control group over time $(\mathrm{P}<0.05)$. In BIS-treated group, an increase in bone density was also observed in the same way as the control group but no significant difference was observed between 2 and 4 weeks (Fig. 8).

Comparing the bone density in same period, bone density is clearly less in BIS-treated group than the control group; significant suppression of bone formation was observed at 1 and 4 weeks $(\mathrm{P}<0.05)$. Nevertheless, no significant difference was obtained between the two groups at 2 weeks (Fig. 8).

\section{CMR image}

One week after extraction, in the control group, the socket is filled with immature bone with irregular mesh and weak calcification (Fig. 9a). The newly formed bone has needle- like structure with low degree of mineralization. In BIS-treated group, newly formed bone in the extraction socket was hardly seen although a small amount of immature bone was detected near the floor of the socket (Fig. 9b).

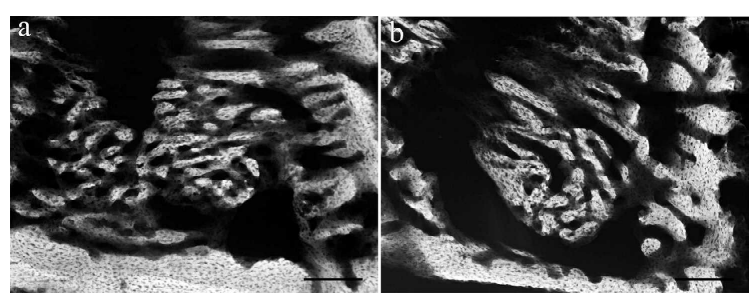

Figure 10. Two weeks after tooth extraction, CMR image. a: Control group: The amount of bone mineralization in the socket increased; the trabecular structure became clear.

b: BIS-treated group: There was an increased in the amount of bone trabeculae compared to 1 week after tooth extraction. Bars $=100 \mu \mathrm{m}$

Two weeks after extraction, in the control group, calcification of bone tissue increased compared to 1 week and the trabecular structure became clear (Fig. 10a). In BIS-treated group, trabecular structure in the socket became clear but it was less than the control group. A thin immature bone was somehow more commonly observed (Fig. 10b).

Four weeks after extraction, in the control group, the extraction socket became unclear, calcification of the bone increased, trabecular structure became thick and dense bone was generally observed (Fig. 11a). In BIS-treated group, compared to 2 weeks, calcification and degree of bone density increased. However, in comparison with the control group at 4 weeks, the bone density was lower and trabecular structure was slightly irregular (Fig. 11b).

\section{Discussion}

\section{New bone formation}

Regarding the formation of new bone, the amount of newly formed bone one week after extraction is clearly less in BIS-treated group than in the control group and low degree of bone mineralization was seen in CMR. The results suggest that BIS administration inhibited new bone formation delaying the healing of extraction socket in the early stage. Moreover, the inhibitory effect influenced the calcification of the newly formed bone. Normally, angiogenesis is enhanced in the early stage of healing of tooth extraction socket with granulation tissue and remarkable invasion of new blood vessels in the socket. Bone formation in tooth extraction socket occurs as osteoblasts derived from undifferentiated mesenchymal cells are present in the granulation tissue although reports showed that BIS administration prevents blood vessel formation having similar results with Alendronate ${ }^{20,21)}$. In other words, the delay in the proliferation of granulation tissue and formation of new blood vessels would also delay the induction of osteoblasts and early formation of new bone.

Postmenopausal osteoporosis is said to be highly rotational and bone resorption is enhanced by the decrease in estrogen concentration $^{22)}$. Cytokines such as TGF- $\beta$ and IGF-1 present in the bone matrix are released during bone formation and by their action, bone formation also increased transiently after a delay in 
bone resorption ${ }^{23)}$. However, in this experiment, the increase in bone density over time was seen in the control group suggesting that bone formation proceeded predominantly even the estrogen level was lowered in active areas such as the extraction socket. On the other hand, only a weak increase in the degree of bone density in BIS-treated group was detected two weeks after extraction. This is because, bone metabolism dropped in BIS-treated group causing a delay in the formation of new bone in the extraction socket suggesting that BIS affected the increase in bone density.

Furthermore, considering the impact in the decline of bone metabolism for the quality of new bone, there is a possibility of the effect of micro-damage as a factor in osteoporosis. Microdamage is a fine crack, which occurs in bone tissue. Bone metabolism is reduced by strong inhibition of bone resorption in BIS-treated group thus accumulation of micro-damage ${ }^{24)}$. BIS has an extended half-life in long bones ${ }^{25,26)}$ and the reduction in bone metabolism is caused by excessive and long-term intake ${ }^{27}$. In the oral cavity, the interalveolar septum is subjected to a lot of load during tooth extraction and accumulation of micro-damage occurs to the jaw since the alveolar bone itself is brittle due to poor bone metabolism than the normal. The newly formed trabecular bone in BIS-treated group was irregular; inflammation may have caused the extensive expansion of granulation tissue in a short period of time, suggesting that it can induce BRONJ.

\section{Abnormality of the osteoclasts}

Many theories have been proposed that the main cause of bone loss is estrogen deficiency leading to increase osteoclasts activation enhancing bone resorption. In the inflammatory cytokine theory, estrogen deficiency caused the production of IL-1, IL-6, TNF- $\beta$, GM-CSF and other inflammatory cytokines ${ }^{28}$. An increase in inflammatory cytokines enhances bone resorption by inhibiting apoptosis, promoting osteoclasts differentiation by M-CSF and RANKL. Also, several studies indicated the possible direct effect of estrogen in osteoclasts ${ }^{29)}$ and the increase in bone resorption caused by an increase in ovarian hormone stimulation ${ }^{30)}$. The path leading to the increase in the activation of osteoclasts by estrogen deficiency is extensive.

In the present study, in both control and BIS-treated groups, a significant difference in the number of TRAP-positive cells between 1 and 2 weeks after extraction was obtained. It was thought that the increase in bone mass was due to healing of the extraction socket together with the rapid remodeling of the bone due to estrogen deficiency and increase in TRAP-positive cells. In BIStreated group, an increase in the number of TRAP-positive cells was observed in comparison with the control group but those TRAP-positive cells were away from the bone surface. A significant difference was observed between the free and attached cells. BIS inhibited the function of osteoclasts in the same manner as cell adhesion ability to the bone surface was decreased.

Osteoclasts adhere to bone surface creating ruffled border during bone resorption. Therefore, it is considered that osteoclasts away from the bone surface are non-functional. Results showed an increase in the number of non-functional osteoclasts in BIStreated group. This is consistent with the findings in one study ${ }^{31)}$. Moreover, the TRAP-positive cells observed in BIS-treated group showed unusual multinucleation with partial or complete lacking of ruffled border compared to the control group. The study showed that estrogen deficiency promoted the differentiation and increase in the number of osteoclasts and BIS promoted apoptosis of osteoclasts ${ }^{12,13)}$ coupled with abnormal cells.

\section{Acknowledgement}

This study was supported in part by the Oral Health Science Center, Tokyo Dental College.

\section{References}

1. Mashiba T, Turner CH, Hirano T, Forwood MR, Johnston $\mathrm{CC}$ and Burr DB. Kinetic studies of bone and mineral metabolism during treatment with (3-amino-1hydroxypropylidene)-1,1-biphosphonate (APD) in rats. Calci Tissue Int 32: 145-157, 1980

2. Ammann P, Rizzoli R, Caverzasio J, Shigematsu T, Slosman $\mathrm{D}$ and Bonjour JP. Effects of the bisphosphonate tiludronate on bone resorption, calcium balance, and bone mineral density. J Bone Mine Res 8: 1491-1498, 1993

3. Ryan PJ, Sherry M, Gibson T and Fogelman I. Treatment of Paget's disease by weekly infusions of 3 aminohydroxypropylidene-1, 1-bisphosphonate (APD). Br J Rheumatol 31: 97-101, 1992

4. Glover D, Lipton A, Keller A, Miller AA, Browning S, Fram RJ, George $S$ and Seaman JJ. Intravenous pamidronate disodium treatment of bone metastases in patients with breast cancer. A dose-seeking study. Cancer 74: 2949-2955, 1994

5. Kohno N. Treatment of breast cancer with bone metastasis: Bisphosphonate treatment - Current and future. Int J Clin Oncol 13: 18-23, 2008

6. Marx RE. Pamidronate (Aredia) and zoledronate (Zometa) induced avascular necrosis of the jaws: a growing epidemic. J Oral Maxillofac Surg 61: 1115-7, 2003

7. Hansen T, Kunkel M, Weber A and James Kirkpatrick C. Osteonecrosis of the jaws in patients treated with bisphosphonates - histomorphologic analysis in comparison with infected osteoradionecrosis. J Oral Pathol Med 35:15560,2006

8. Filleul O, Crompot E and Saussez S. Bisphosphonate-induced osteonecrosis of the jaw: a review of 2,400 patient cases. $\mathrm{J}$ Cancer Res Clin Oncol 136:1117-24. 2010

9. Lo JC, O'Ryan FS, Gordon NP, Yang J, Hui RL, Martin D, 
Takaki Yamazaki et al: Effect of Bisphosphonate after Tooth Extraction in Ovariectomized Rats Hutchinson M, Lathon PV, Sanchez G, Silver P, Chandra M, McCloskey CA, Staffa JA, Willy M, Selby JV and Go AS. Prevalence of osteonecrosis of the jaw in patients with oral bisphosphonate exposure. J Oral Maxillofac Surg 68: 24353, 2010

10. Vahtsevanos K, Kyrgidis A, Verrou E, Katodritou E, Triaridis $\mathrm{S}$, Andreadis CG, Boukovinas I, Koloutsos GE, Teleioudis Z, Kitikidou K, Paraskevopoulos P, Zervas K and Antoniades $\mathrm{K}$. Longitudinal cohort study of risk factors in cancer patients of bisphosphonate-related osteonecrosis of the jaw. J Clin Oncol 27: 5356-62, 2009

11. Assael LA. Oral bisphosphonates as a cause of bisphosphonate-related osteonecrosis of the jaws: clinical findings, assessment of risks, and preventive strategies. J Oral Maxillofac Surg 67 (5 Suppl): 35-43, 2009

12. Mönkkönen H, Auriola S, Lehenkari P, Kellinsalmi M, Hassinen IE, Vepsäläinen J and Mönkkönen J. A new endogenous ATP analog (ApppI) inhibits the mitochondrial adenine nucleotide translocase (ANT) and is responsible for the apoptosis induced by nitrogen-containing bisphosphonates. Br J Pharmacol 147: 437-45, 2006

13. Fleisch H. Development of bisphosphonates. Breast Cancer Res 4: 30-4, 2002

14. Ernberg M and Kopp S. Effect of alendronate on risk of fracture in women with low bone density but without vertebral fractures: results from the Fracture Intervention Trial. J Am Med Ass 280: 2077-82. 1998

15. Levis $\mathrm{S}$ and Theodore G. Summary of AHRQ's comparative effectiveness review of treatment to prevent fractures in men and women with low bone density or osteoporosis: update of the 2007 report. J Manag Care Pharm. 18 (4 Suppl B): S1-15, 2012

16. Black DM, Cummings SR, Karpf DB, Cauley JA, Thompson DE, Nevitt MC, Bauer DC, Genant HK, Haskell WL, Marcus R, Ott SM, Torner JC, Quandt SA, Reiss TF and Ensrud KE. Randomised trial of effect of alendronate on risk of fracture in women with existing vertebral fractures. Fracture intervention trial research group. Lancet 348: 1535-41, 1996

17. Azuma Y, Sato H, Oue Y, Okabe K, Ohta T, Tsuchimoto M and Kiyoki M. Alendronate distributed on bone surfaces inhibits osteoclastic bone resorption in vitro and in experimental hypercalcemia models. Bone 16: 235-45, 1995

18. Lelovas PP, Xanthos TT, Thoma SE, Lyritis GP and Dontas IA. The laboratory rat as an animal model for osteoporosis research. Comp Med 58: 424-30, 2008

19. Jee WS and Yao W. Overview: animal models of osteopenia and osteoporosis. J Musculoskelet Neuronal Interact 1: 193207. 2001

20. Kobayashi Y, Hiraga T, Ueda A, Wang L, Matsumoto-

Nakano M, Hata K, Yatani H and Yoneda T. Zoledronic acid delays wound healing of the tooth extraction socket, inhibits oral epithelial cell migration, and promotes proliferation and adhesion to hydroxyapatite of oral bacteria, without causing osteonecrosis of the jaw, in mice. J Bone Miner Metab 28: 165-75. 2010

21. Aguirre JI, Altman MK, Vanegas SM, Franz SE, Bassit AC and Wronski TJ. Effects of alendronate on bone healing after tooth extraction in rats. Oral Dis 16: 674-85, 2010

22. Pacifici R, Brown C, Puscheck E, Friedrich E, Slatopolsky E, Maggio D, McCracken R and Avioli LV. Effect of surgical menopause and estrogen replacement on cytokine release from human blood mononuclear cells. Proc Natl Acad Sci USA 88: 5134-8, 1991

23. Pfeilschifter J, Bonewald L and Mundy GR. Characterization of the latent transforming growth factor beta complex in bone. J Bone Miner Res 5: 49-58, 1990

24. Mashiba T, Turner CH, Hirano T, Forwood MR, Johnston $\mathrm{CC}$ and Burr DB. Effects of suppressed bone turnover by bisphosphonates on microdamage accumulation and biomechanical properties in clinically relevant skeletal sites in beagles. Bone 28: 5247531, 2001

25. Watts NB and Diab DL. Long-term use of bisphosphonates in osteoporosis (Review). J ClinEndocrinolMetab 95: 155565, 2010

26. Porras AG, Holland SD, Gertz BJ. Pharmacokinetics of alendronate (Review) Clin Pharmacokinet 36: 315-28, 1999

27. Odvina CV, Zerwekh JE, Rao DS, Maalouf N, Gottschalk FA and Pak CY. Severely suppressed bone turnover: a potential complication of alendronate therapy. J Clin Endocrinol Metab 90: 1294-1301, 2005

28. Pfeilschifter J, Köditz R, Pfohl M and Schatz H. Changes in proinflammatory cytokine activity after menopause. Endocr Rev 23: 90-119, 2002

29. Nakamura T, Imai Y, Matsumoto T, Sato S, Takeuchi K, Igarashi K, Harada Y, Azuma Y, Krust A, Yamamoto Y, Nishina H, Takeda S, Takayanagi H, Metzger D, Kanno J, Takaoka K, Martin TJ, Chambon P and Kato S. Estrogen prevents bone loss via estrogen receptor alpha and induction of Fas ligand in osteoclasts. Cell 130: 811-23, 2007

30. Sun L, Peng Y, Sharrow AC, Iqbal J, Zhang Z, Papachristou DJ, Zaidi S, Zhu LL, Yaroslavskiy BB, Zhou H, Zallone A, Sairam MR, Kumar TR, Bo W, Braun J, Cardoso-Landa L, Schaffler MB, Moonga BS, Blair HC and Zaidi M. FSH directly regulates bone mass. Cell 125: 247-60, 2006

31. Weinstein RS, Roberson PK and Manolagas SC. Giant osteoclast formation and long-term oral bisphosphonate therapy. N Eng J Med 360: 53-62, 2009 
J.Hard Tissue Biology Vol. 22(4):493-500, 2013 